\title{
Stargazin Modulates Native AMPA Receptor Functional Properties by Two Distinct Mechanisms
}

\author{
Dorothy Turetsky, ${ }^{\star}$ Eva Garringer, ${ }^{\star}$ and Doris K. Patneau \\ Department of Anatomy and Cell Biology, Oklahoma State University Center for Health Sciences, Tulsa, Oklahoma 74107
}

\begin{abstract}
AMPA receptors play a central role in basal excitatory synaptic transmission as well as synaptic maturation and plasticity. The transmembrane AMPA receptor regulatory protein (TARP) stargazin $(\gamma 2)$ serves multiple roles in trafficking and stabilizing synaptic AMPA receptors and may be incorporated as an auxiliary subunit. We wanted to determine whether stargazin altered channel function of neuronal AMPA receptors. Transfection of cultured hippocampal neurons with stargazin produced two distinct effects on AMPA receptor functional properties: a sixfold reduction in glutamate-evoked desensitization and a twofold increase in the relative size of responses to the partial agonist kainate. Kinetic and dose-response analyses suggest that the effect of stargazin on glutamate desensitization results from an allosteric interaction that destabilizes the desensitized state of the receptor and that potentiation of kainate responses reflects increased efficacy rather than a change in affinity. These functional effects were also observed in human embryonic kidney 293 cells transfected with various heteromeric and homomeric AMPA receptors, with distinct subunit-dependent effects on glutamate desensitization, kainate efficacy, and trafficking. Two regions of stargazin mediate its functional effects: the C-terminal intracellular domain seems to be more important for effects on glutamate-evoked desensitization and receptor trafficking, whereas the first extracellular domain makes a larger contribution to effects on kainate efficacy. These data indicate that TARPs are involved both in trafficking and direct modulation of channel function and, as auxiliary subunits of neuronal AMPA receptors, must be considered in the functional heterogeneity of neuronal AMPA receptors.
\end{abstract}

Key words: stargazin; AMPA receptor; desensitization; kainate; TARP; trafficking

\section{Introduction}

AMPA receptors mediate the majority of fast excitatory transmission in the mammalian CNS and play a crucial role in synaptic plasticity. AMPA receptors are assembled as tetramers, composed of various combinations of the subunits GluR-A, B, C, and D (Keinanen et al., 1990), also termed GluR-1, 2, 3, and 4 (Boulter et al., 1990). Subunit and splice variant composition can affect receptor biophysical properties such as desensitization (Sommer et al., 1990), single-channel conductance (Swanson et al., 1997), and $\mathrm{Ca}^{2+}$ permeability (Hollmann et al., 1991; Sommer et al., 1991). Although several cytosolic AMPA receptorassociated proteins have been described that are involved in controlling insertion, removal, and stabilization of AMPA receptors at the synapse (for review, see Bredt and Nicoll, 2003), none of these directly changes receptor biophysical properties. However, evidence that the glutamate receptor binding protein postsynaptic density-95 (PSD-95) decreases kainate receptor desensitization (Garcia et al., 1998) and increases NMDA receptor open-

Received March 21, 2005; revised July 5, 2005; accepted July 6, 2005.

This work was supported by a grant from the Oklahoma Center for the Advancement of Science and Technology. We thank Melisa Gulick for technical assistance. We also thank Drs. Earl Blewett and Andres Buonanno for invaluable molecular biology advice.

*D.T. and E.G. contributed equally to this work.

Correspondence should be addressed to Dr. Doris K. Patneau, Oklahoma State University Center for Health Sciences, 1111 West 17th Street, Tulsa, 0K 74107. E-mail: dkpatneau@chs.okstate.edu.

DOI:10.1523/JNEUROSCI.1108-05.2005

Copyright $\odot 2005$ Society for Neuroscience $\quad$ 0270-6474/05/257438-11\$15.00/0 channel probability (Lin et al., 2004) suggests an associated protein could alter AMPA receptor function.

Stargazin, which is disrupted in the stargazer mutant mouse, was characterized initially by homology as the second member $(\gamma 2)$ of the voltage-gated calcium channel $\gamma$ subunit family (Letts et al., 1998). The stargazer mice display a profound deficit in AMPA receptor-mediated EPSCs in cerebellar granule cells (Hashimoto et al., 1999), a phenotype that can be rescued by overexpression of $\gamma 2$ (Chen et al., 2000). Three closely related isoforms, $\gamma 3, \gamma 4$, and $\gamma 8$, which show distinct patterns of expression, have also been identified as transmembrane AMPA receptor regulatory proteins (TARPs) based on their ability to restore AMPA receptor-mediated currents in stargazer cerebellar granule cells (Tomita et al., 2003). $\gamma 2$ has three apparent functions in AMPA receptor trafficking: (1) facilitating surface receptor delivery as a molecular chaperone involved in correct folding and endoplasmic reticulum processing of AMPA receptors (Vandenberghe et al., 2005b); (2) stabilizing AMPA receptors on the cell surface (Tomita et al., 2004); and (3) targeting AMPA receptors to the synapse via interactions with PSD-95 and n-PIST (the neuronal isoform of protein interacting with TC-10) (Chen et al., 2000; Cuadra et al., 2004).

TARPs have been shown recently to copurify with neuronal AMPA receptors (Nakagawa et al., 2005; Vandenberghe et al., 2005a), suggesting that they may function as auxiliary subunits of the receptor. Because auxiliary subunits in voltage-gated channels can affect channel properties, we examined the effects of 
stargazin on channel function of neuronal AMPA receptors. During the course of our work, two short reports appeared that addressed the effects of stargazin on recombinant AMPA receptors. Yamazaki et al. (2004) reported that stargazin enhanced glutamate-evoked currents in human embryonic kidney 293 (HEK293) cells and Xenopus oocytes expressing GluR-A or GluR-B homomeric receptors and that other TARPs had a similar effect. More recently, Priel et al. (2005) showed that stargazin slowed both desensitization and deactivation of glutamateevoked responses. We wanted to further characterize the effects of stargazin on the functional properties of native AMPA receptors and gain insight into the molecular mechanisms underlying these effects.

\section{Materials and Methods}

Primary cultures of hippocampal neurons. Primary cultures of hippocampal neurons were prepared according to established methods (Ihle and Patneau, 2000). Briefly, hippocampal tissue dissected from the brains of newborn [postnatal day 0 (P0) to P1] Sprague Dawley rats was incubated in papain and dissociated by trituration with a glass pipette. Cells were resuspended at a density of $2.5-5 \times 10^{6}$ per milliliter in DMEM high glucose supplemented with $5 \%$ horse serum, $1 \%$ fetal bovine serum (FBS), 2 mm Glutamax (Invitrogen, Grand Island, NY), $13 \mu \mathrm{g} / \mathrm{ml} 5^{\prime}$ fluorodeoxyuridine, and 1\% N3 neuronal supplement (Romijn et al., $1981)$ and plated on a pre-existing glial monolayer. Cultures were maintained in a humidified $37^{\circ} \mathrm{C}, 10 \% \mathrm{CO}_{2}$ incubator. All experiments were performed after $7 \mathrm{~d}$ in vitro.

Glial monolayers were generated by dissociating hippocampi as above. Cells were resuspended in DMEM supplemented with 10\% FBS, $2 \mathrm{~mm}$ Glutamax, and $1 \%$ penicillin/streptomycin and plated at a density of $1 \times$ $10^{5}$ cells per milliliter on $35 \mathrm{~mm}$ tissue culture dishes precoated with poly-L-lysine $(0.01 \%$ solution). These conditions inhibit neuronal survival and allow glial cell proliferation. After the glial monolayer reached confluence, $33 \mu \mathrm{g} / \mathrm{ml}$ uridine and $13 \mu \mathrm{g} / \mathrm{ml}^{\prime}$-fluorodeoxyuridine were added to the culture medium to inhibit mitosis.

Mouse cerebellar granule cell cultures. Primary cultures of cerebellar granule neurons were prepared as described previously (Bito et al., 2000). Briefly, cerebella were dissected from P2 Swiss Webster mice, incubated in trypsin, and dissociated by trituration with a glass pipette. Cells were resuspended in minimal essential medium with Earle's salts (MEM; supplied without glutamine or phenol red) supplemented with 10\% FBS, 2 mM glutamine, $25 \mu \mathrm{g} / \mathrm{ml}$ insulin, and 2\% B27 (Invitrogen) and plated at a density of 1.6 cerebella per $35 \mathrm{~mm}$ dish. Dishes were coated with polyD-lysine $(100 \mathrm{ng} / \mathrm{ml})$ and laminin $(4 \mathrm{ng} / \mathrm{ml}) 24 \mathrm{~h}$ before the dissection. On the second day, in vitro cultures were fed with MEM supplemented with 5\% FBS, $0.5 \mathrm{~mm}$ glutamine, $25 \mu \mathrm{g} / \mathrm{ml}$ insulin, $2 \% \mathrm{~B} 27$, and $10 \mu \mathrm{M}$ cytosine arabinoside to inhibit glial division. Afterward, cells were fed every 3-4 d with the 5\% FBS medium, lacking Ara C. Cultures were maintained in a humidified $37^{\circ} \mathrm{C}, 5 \% \mathrm{CO}_{2}$ incubator. Note that these cultures were both plated and maintained in normionic $\mathrm{K}^{+}$. All experiments were performed at $7 \mathrm{~d}$ in vitro.

Neuronal transfection. Hippocampal or cerebellar granule neurons were transfected at $5 \mathrm{~d}$ in vitro using Lipofectamine 2000 (Invitrogen). For each $35 \mathrm{~mm}$ dish to be transfected, $4 \mu \mathrm{g}$ of Qiagen (Hilden, Germany)-purified plasmid DNA and $2 \mu \mathrm{l}$ of lipid were diluted separately into $50 \mu \mathrm{l}$ of DMEM and incubated for $5 \mathrm{~min}$ at room temperature. The diluted DNA and lipid were then combined and incubated for an additional $20 \mathrm{~min}$ at room temperature. Before transfection, cells were washed with fresh media and left in $\sim 1 \mathrm{ml}$ of this media. One hundred microliters of DNA/lipid complexes were added to the culture dish, and the dishes were returned to their respective incubators. After $\sim 16 \mathrm{~h}$, an additional $1 \mathrm{ml}$ of fresh media was added to the culture to dilute the lipid. For all neuronal experiments, enhanced green fluorescent protein (pEGFP; Clontech, Palo Alto, CA) was included to allow identification of transfected cells during subsequent electrophysiology experiments. The $\gamma$ :GFP ratio was 3:1, with control dishes receiving $4 \mu \mathrm{g}$ of GFP. Electrophysiology experiments were conducted $\sim 40 \mathrm{~h}$ after the start of transfection.
HEK293 transfection. HEK293 cells were obtained from American Type Culture Collection (Manassas, VA). Cells were grown in MEM supplemented with $10 \% \mathrm{FBS}$ and were maintained in a humidified $37^{\circ} \mathrm{C}$, $5 \% \mathrm{CO}_{2}$ incubator. Transfections were performed using Lipofectamine (Invitrogen). For each $35 \mathrm{~mm}$ dish to be transfected, $2 \mu \mathrm{g}$ of Qiagenpurified DNA and $8 \mu$ l of Lipofectamine were diluted in OPTI-MEM (Invitrogen) and incubated for $20 \mathrm{~min}$ at room temperature. Culture media were replaced with this transfection solution, and cells were returned to the $37^{\circ} \mathrm{C}$ incubator for $3 \mathrm{~h}$. Afterward, the DNA/lipid complexes were washed off the cells, and cultures were fed with MEM plus $10 \%$ FBS containing $30 \mu \mathrm{M}$ 2,3-dihydroxy-6-nitro-7-sulfamoylbenzo(F)quinoxaline (NBQX) to block activation of expressed AMPA receptors by traces of glutamate in the medium. Electrophysiology experiments were conducted $\sim 48 \mathrm{~h}$ after transfection. For experiments with homomeric AMPA receptors, the ratio of Glu-R: $\gamma$ :PSD-95:pEGFP was $1: 1: 1: 0.64(0.55 \mu \mathrm{g}+0.55 \mu \mathrm{g}+0.55 \mu \mathrm{g}+0.35 \mu \mathrm{g}=2 \mu \mathrm{g})$, with conditions not containing a $\gamma$ subunit and/or PSD-95 having additional GFP added to compensate. For heteromeric receptors, a ratio of GluRA:GluR-B: $\gamma:$ pEGFP of 1:1.5:1.5:0.5 was used to ensure that all receptors included a GluR-B subunit.

Construct generation. Cacng2 $(\gamma 2)$ was cloned from adult rat cerebellum, and Cacng3 ( $\gamma 3)$ and Cacng5 ( $\gamma 5)$ were cloned from adult rat forebrain total RNA using the ProSTAR Ultra HF RT-PCR system (Stratagene, La Jolla, CA) and the following primers: $\gamma 2$ forward, $5^{\prime}$-ATGGGGCTGTTTGATCGAGGTG-3'; $\gamma 2$ reverse, 5'-TCATACGGGCGTGGTCCGGCG-3'; $\gamma 3$ forward, $5^{\prime}$-ATGAGGATGTGTGACAGAGGTATCC- $5^{\prime} ; \gamma 3$ reverse, $5^{\prime}$-TCAGACGGGCGTGGTGCGTCT-3'; $\gamma 5$ forward, 5'-ATGAGCACCTGTGGGAGGAAGGC-3'; $\gamma 5$ reverse, $5^{\prime}$ TCAGCAGGGAGATGATGACATCTGG-3'. All three PCR products were subsequently subcloned into the expression vector pCMV-Script (Stratagene) and sequenced for verification at the Recombinant DNA/ Protein Resource Facility at Oklahoma State University (Stillwater, OK). The $\gamma 2 / \gamma 5$ chimeras $\gamma 2(\Delta 26-103) / \gamma 5($ ins $26-99)$ and $\gamma 2(\Delta 89-103) /$ $\gamma 5$ (ins85-99) were generated by taking advantage of unique $B s a B I, B b s \mathrm{I}$, and $X h o I$ sites in $\gamma 2$ at nucleotide positions 72,257 , and 308, respectively. Both constructs were assembled originally in pGEM-T Easy (Promega, Madison, WI) and later transferred by PCR into pCMV-Script. The C-terminal truncations $\gamma 2(1-212), \gamma 2(1-244)$, and $\gamma 2(1-288)$ were generated by PCR using the $\gamma 2$ forward primer (above) and the reverse primers 5' ${ }^{\prime}$-TCAGGCCGTGGCCCGCAGCTGTTTG-3', 5'-TCAGGTGGAGCGCGAGCTGGAGCGG-3', and 5'-TCAGTAGGTGGCGATGGGCGTGGTGG-3', respectively, and subcloned into pCMV-Script. Expression constructs for GluR- $A_{i},-B_{i},-B_{o},-C_{i}$, and $-D_{i}$ were a generous gift from Dr. P. H. Seeburg (Max Planck Institute for Medical Research, Heidelberg, Germany). For all constructs used in these experiments, expression was driven by the cytomegalovirus promoter/enhancer.

Electrophysiology. Whole-cell patch-clamp recordings were performed at room temperature $\left(23-25^{\circ} \mathrm{C}\right)$, with cells voltage clamped at $-60 \mathrm{mV}$. Recording electrodes were pulled from borosilicate glass and fire-polished; typical electrode resistance in series with the cell was 2-7 M $\Omega$ and was compensated by $60-80 \%$ using an Axopatch 200 A patch-clamp amplifier (Molecular Devices, Foster City, CA). Recorded data were filtered at $1-3 \mathrm{kHz}$ and sampled at $2-10 \mathrm{kHz}$ using pClamp (Molecular Devices).

Extracellular saline for neuronal experiments contained $160 \mathrm{~mm} \mathrm{NaCl}$, $2.5 \mathrm{~mm} \mathrm{KCl}, 10 \mathrm{~mm}$ HEPES, $10 \mathrm{~mm}$ glucose, $2 \mathrm{~mm} \mathrm{CaCl}_{2}, 1 \mathrm{~mm} \mathrm{MgCl}_{2}$, and $0.01 \mathrm{mg} / \mathrm{ml}$ phenol red. Osmolarity was adjusted to $325 \mathrm{mOsm}$, and the $\mathrm{pH}$ was titrated to 7.3 with $\mathrm{NaOH}$. Tetrodotoxin ( $400 \mathrm{~nm}$ to $1 \mu \mathrm{M})$, bicuculline (5-10 $\mu \mathrm{M})$, and $(5 S, 10 R)-(+)$-5-methyl-10,11-dihydro- $5 H$ dibenzo [a,d] cyclohepten-5,10-imine maleate (MK-801) (5 $\mu \mathrm{M})$ were added to block voltage-gated sodium channels, $\mathrm{GABA}_{\mathrm{A}}$ receptors, and NMDA receptors, respectively. Intracellular solution for neurons contained the following (in mM): $125 \mathrm{CsMeSO}_{3}, 15 \mathrm{CsCl}, 10$ HEPES, 5 $\mathrm{Cs}_{4} \mathrm{BAPTA}, 0.5 \mathrm{CaCl}_{2}, 3 \mathrm{MgCl}_{2}$, and $2 \mathrm{Na}_{2} \mathrm{ATP}$. Extracellular saline for HEK293 cells contained $145 \mathrm{~mm} \mathrm{NaCl}, 5.4 \mathrm{~mm} \mathrm{KCl}, 1 \mathrm{~mm} \mathrm{MgCl}_{2}, 1.8 \mathrm{~mm}$ $\mathrm{CaCl}_{2}, 5 \mathrm{~mm}$ HEPES, and $0.01 \mathrm{mg} / \mathrm{ml}$ phenol red. The osmolarity was adjusted to $295 \mathrm{mOsm}$, and the $\mathrm{pH}$ was adjusted to 7.3 with $\mathrm{NaOH}$. Kynurenate $(500 \mu \mathrm{M})$ was added to the bath to protect cells from preexposure to agonists. Patch pipettes were filled with an intracellular so- 
lution containing the following (in mM): $135 \mathrm{CsCl}, 10 \mathrm{CsF}, 2 \mathrm{MgCl}_{2}, 0.5$ $\mathrm{CaCl}_{2}, 5 \mathrm{Cs}_{4}$ BAPTA, 10 HEPES, and $2 \mathrm{Na}_{2} \mathrm{ATP}$.

Rapid agonist application was achieved using a glass flowpipe array (12 parallel barrels, each $400 \mu \mathrm{m}$ in diameter; Garner Glass, Claremont, CA) placed directly in front of a voltage-clamped cell. Solutions were driven by a peristaltic pump (Minipuls3; Gilson Medical Electric, Middleton, WI) through three-way solenoid valves (Isolatch; General Valve, Fairfield, NJ). Valve opening and closing was coordinated with flowpipe movement using the Warner Instruments (Hamden, CT) SF-77B Perfusion Fast-Step system and custom valve controller. This system can achieve solution exchange around a small cell within 5-10 ms.

Analysis. Clampfit (Molecular Devices) was used for peak, steady-state amplitude, and kinetic measurements of electrophysiological data. As an assay for inclusion of GluR-B in heteromeric GluR-A/B receptors in HEK293 cells, +40:-60 rectification ratios for glutamate peak were calculated, and cells with a rectification ratio of $<0.5$ were excluded from the data set. As a functional assay for AMPA surface expression, we calculated maximal current density by dividing peak current evoked by 3 mu glutamate and $500 \mu \mathrm{M}$ trichlormethiazide (TCM) by whole-cell capacitance (picoampere per picofarad). Although cyclothiazide is the drug most commonly used to block AMPA receptor desensitization, the related benzothiadiazine TCM blocks glutamate-evoked desensitization in hippocampal neurons to a similar degree as cyclothiazide ( $96 \pm 4 \%$ of peak response to glutamate in the presence of $100 \mu \mathrm{M}$ cyclothiazide; $n=$ 14) and has the advantage of faster association and dissociation kinetics. Time constants for onset of desensitization, association, and dissociation of kainate and onset of potentiation by TCM were determined by exponential fits using a Chebyshev algorithm. Time constants for TCM dissociation were calculated from $50 \%$ decay times relative to glutamate steady-state response $(\tau=50 \%$ decay time/0.69). The validity of this method was verified in selected cells in which longer recovery times were well fit with a single exponential function. Because glutamate peaks in whole-cell recordings can be affected by desensitization, both percentage of desensitization and current density were determined relative to maximum glutamate-evoked responses in the presence of the positive allosteric modulator TCM. Statistical analyses were performed using SPSS (SPSS, Chicago, IL). Unless noted otherwise, all significance was determined by ANOVA, followed by planned comparisons using a Bonferroni's post hoc test.

Surface biotinylation. AMPA receptor surface expression was measured using the membrane-impermeant biotinylation reagent NHS-SSbiotin (Pierce, Rockford, IL), essentially as described by Mammen et al. (1997). Sister cultures from the same transfections used in electrophysiological experiments were gradually cooled to $4^{\circ} \mathrm{C}$ with partial washes in cool PBS $/ \mathrm{Ca}^{2+} / \mathrm{Mg}^{2+}$ (in mM: 10 phosphate buffer, $137 \mathrm{NaCl}, 1 \mathrm{CaCl}_{2}$, and $0.5 \mathrm{MgCl}_{2}, \mathrm{pH} 7.4$ ). Cells were then incubated at $4^{\circ} \mathrm{C}$ in ice-cold biotinylation solution ( $1 \mathrm{mg} / \mathrm{ml}$ NHS-SS-biotin in PBS $/ \mathrm{Ca}^{2+} / \mathrm{Mg}^{2+}$ ) for $15 \mathrm{~min}$. Each $35 \mathrm{~mm}$ dish was washed three times in precipitation buffer (PB; $10 \mathrm{~mm} \mathrm{NaPO}_{4}$, pH 7.4, 5 mм EDTA, 5 mм EGTA, 100 mм NaCl, 1 mм $\mathrm{Na}_{3} \mathrm{VO}_{4}, 50 \mathrm{~mm} \mathrm{NaF}, 10 \mathrm{~mm}$ sodium pyrophosphate, $20 \mathrm{ng} / \mathrm{ml}$ aprotinin, and $20 \mathrm{ng} / \mathrm{ml}$ leupeptin) containing $1 \%$ bovine serum albumin and solubilized in $166 \mu \mathrm{l}$ of $\mathrm{PB}$ containing 1\% SDS. Dishes were then rinsed with $833 \mu \mathrm{l}$ of PB containing 1\% Triton X-100, and the SDS and Triton fractions were combined. Samples were sonicated and spun at $16,000 \times$ $g$ for $20 \mathrm{~min}$, and supernatants were removed to a fresh tube and frozen at $-80^{\circ} \mathrm{C}$. To precipitate biotinylated surface proteins, $200 \mu \mathrm{l}$ streptavidin beads (Ultralink Immobilized Streptavidin Plus; Pierce) were added to each sample, and samples were placed on a rotator for $2 \mathrm{~h}$ at $4^{\circ} \mathrm{C}$. Afterward, $200 \mu \mathrm{l}$ of the mixed sample was removed and mixed with $100 \mu \mathrm{l}$ of $3 \times$ sample buffer (total protein sample). The remaining $1 \mathrm{ml}$ was spun in a microfuge, and the supernatant was removed and mixed with $400 \mu \mathrm{l}$ of $3 \times$ sample buffer (intracellular protein fraction). The beads were then washed sequentially in $800 \mu \mathrm{l}$ of $\mathrm{PB} / 1 \%$ Triton, $800 \mu \mathrm{l}$ of $\mathrm{PB} / 1 \%$ Triton/ $500 \mathrm{~mm}$ added $\mathrm{NaCl}$, and $800 \mu \mathrm{l}$ of $\mathrm{PB}$. After the last wash was removed, the beads were resuspended in $1 \mathrm{ml}$ of $1 \times$ sample buffer (surface protein fraction). All samples were boiled for 3 min to elute protein, and beads were spun down from the total and surface samples. Equal volumes of each sample were then loaded on a 7\% Tris acetate gel (Novex, San Diego,
CA), along with a dilution series of the control total protein sample. Proteins were resolved on the gel and transferred to Invitrolon polyvinylidene difluoride membrane (Invitrogen), and a Western blot was performed for the protein of interest. Proteins were visualized with ECL Plus (Amersham Biosciences, Piscataway, NJ) on a Storm phosphorimager (Amersham Biosciences). Bands were quantitated using ImageQuant, and the total protein dilution series was used to generate a standard curve for each experiment. For some experiments, blots were stripped and reprobed with a tubulin antibody to verify that cells remained intact during the biotinylation reaction and that all biotin was washed away before solubilization. GluR-1 (AB1504; final dilution, 1:200), GluR-2 (AB1506; final dilution, 1:400), and $\beta$-tubulin (MAB3408; final dilution, 1:1000) antibodies were purchased from Chemicon (Temecula, CA).

Materials. Tetrodotoxin was purchased from Calbiochem (La Jolla, $\mathrm{CA}$ ), and $\mathrm{Cs}_{4} \mathrm{BAPTA}$ was purchased from Molecular Probes (Eugene, OR). Kainate, NBQX, kynurenate, MK-801, and bicuculline were purchased from Tocris Cookson (Ellisville, MO). All other reagents were obtained from Sigma (St. Louis, MO) or as noted above.

\section{Results}

\section{Stargazin decreases desensitization and increases kainate efficacy at hippocampal AMPA receptors}

Although stargazin-mediated increases in AMPA receptor currents have traditionally been interpreted as reflecting its effects on AMPA receptor trafficking, it also seemed possible, given the potential role of stargazin $(\gamma 2)$ as an auxiliary subunit, that it could additionally affect receptor functional properties. We therefore examined the effects of exogenous $\gamma 2$ expression on AMPA receptor function in hippocampal neurons using fast perfusion techniques during whole-cell voltage-clamp recording. To minimize the contribution of endogenous $\gamma 2$, dissociated cultures were prepared from newborn rat pups, and recordings were done at $7 \mathrm{~d}$ in vitro. [Note that $\gamma 3$ and $\gamma 8$ are the predominant TARPs expressed in the hippocampus and that neuronal TARP expression increases during the second and third postnatal weeks (Tomita et al., 2003).] Exogenous $\gamma 2$ increased normalized steady-state glutamate responses more than sixfold relative to controls (Fig. 1A,B), decreasing desensitization from $98.3 \pm$ $0.2 \%$ to $87.8 \pm 1.5 \%$ (mean \pm SEM; $n=21$ for each group). Additionally, exogenous $\gamma 2$ more than doubled the relative size of currents evoked by the weakly desensitizing partial agonist kainate. It is striking that although kainate currents in hippocampal neurons are typically only $40 \%$ as large as peak glutamate responses (Fig. $1 \mathrm{~A}, \mathrm{C}$ ), they approached parity in cells overexpressing $\gamma 2$.

Maximal glutamate currents were determined by blocking desensitization with the benzothiadiazine TCM (see Materials and Methods) and normalized for whole-cell capacitance as a functional assay for surface AMPA receptor expression. Exogenous $\gamma 2$ expression failed to increase AMPA receptor current density in hippocampal neurons (Fig. 1D). Thus, in a system in which exogenous $\gamma 2$ did not significantly alter surface expression of native AMPA receptors as determined in a functional assay, it nonetheless clearly altered receptor functional properties as evidenced by both reduced desensitization of glutamate responses and increased apparent efficacy of kainate. Although Schnell et al. (2002) reported an increase in AMPA receptor trafficking in $\gamma 2$ transfected hippocampal slice cultures, their observation of a fivefold increase in AMPA-evoked steady-state responses is in good agreement with the sixfold increase in the glutamate steadystate current that we found in transfected hippocampal neurons. Schnell et al. (2002) interpreted this result as increased AMPA receptor surface trafficking by $\gamma 2$; however, our results are most consistent with a change in receptor desensitization and suggest 


\section{A Hippocampal Neurons}
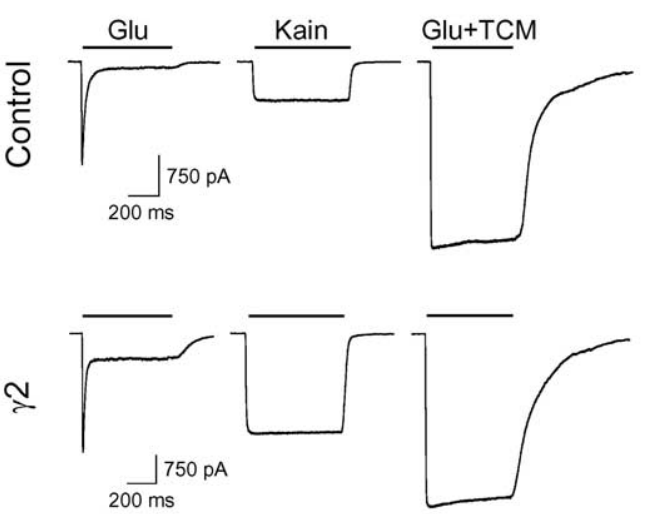
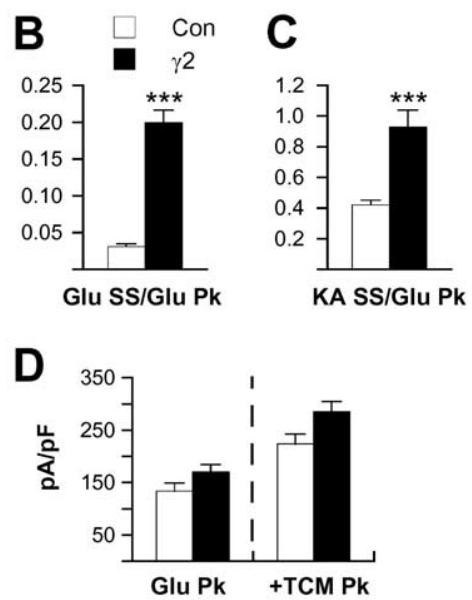

Figure 1. $\quad \gamma 2$ selectively potentiates steady-state glutamate and kainate-evoked currents in hippocampal neurons. $\boldsymbol{A}, \mathrm{Re}-$ sponses of representative hippocampal neurons transfected with GFP alone (control) or $\gamma 2$ plus GFP to 3 mm glutamate, $600 \mu \mathrm{M}$ kainate (Kain), and glutamate in the presence of $500 \mu \mathrm{M}$ TCM (Glu + TCM). Steady-state currents evoked by glutamate $(\boldsymbol{B})$ or kainate $(\mathrm{KA} ; \boldsymbol{C})$ in hippocampal neurons were normalized to the peak glutamate response to assess changes in AMPA receptor functional properties. $\boldsymbol{D}$, Current density was determined by normalizing peak glutamate currents in the presence of TCM to whole-cell capacitance as a functional measure of AMPA receptor surface expression. For comparison, normalized glutamate peak currents are also graphed. The error bars in $\boldsymbol{B}-\boldsymbol{D}$ represent the mean $\pm \mathrm{SEM}\left(n=21\right.$ for each group). ${ }^{* * *} p<0.001$, significant difference from corresponding control. Glu, Glutamate; Con, control; SS, steady state; Pk, peak.

A

\section{Cerebellar Granule Cells}
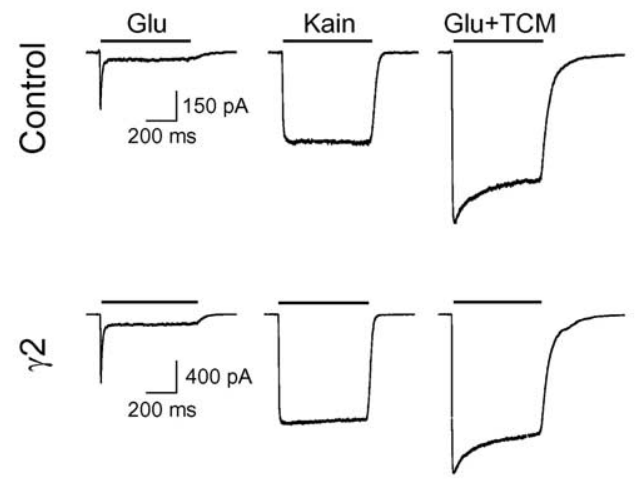
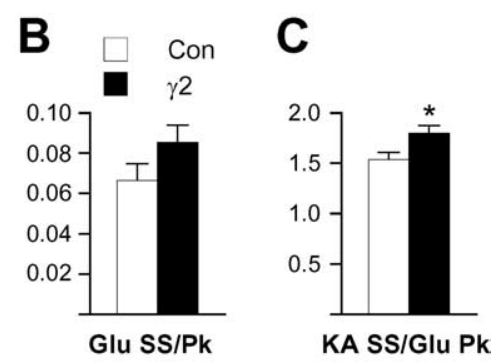

D

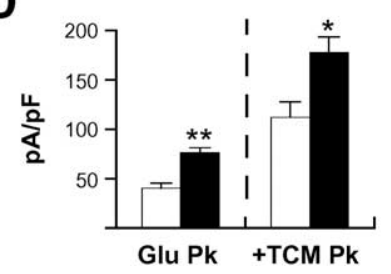

Figure 2. $\quad \gamma 2$ increases receptor surface expression in cerebellar granule neurons with minimal functional effects. $\boldsymbol{A}$, Traces from representative cerebellar granule cells transfected with GFP or $\gamma 2$ plus GFP illustrate the large kainate (Kain) responses characteristic of these neurons and the relatively smaller functional effects of exogenous $\gamma 2$ expression. Steady-state currents evoked by glutamate ( $3 \mathrm{~mm} ; \boldsymbol{B})$ or kainate $(600 \mu \mathrm{m} ; \boldsymbol{C})$ were normalized to the peak glutamate response to assess changes in AMPA receptor functional properties. $D$, Current density was determined by normalizing peak glutamate currents in the presence of TCM to whole-cell capacitance as a functional measure of AMPA receptor surface expression. The error bars in $\boldsymbol{B}-\boldsymbol{D}$ represent the mean \pm SEM $(n=12-15)$. ${ }^{*} p<0.05,{ }^{* *} p<0.01$, difference for $\gamma 2$ relative to the respective control. Glu, Glutamate; Con, control; SS, steady state; Pk, peak.

that trafficking in these cultured hippocampal neurons is already saturated by endogenous TARP expression.

\section{Exogenous stargazin increases current density in cerebellar} granule cells with minimal functional effects

In contrast to the expression of multiple TARPs in hippocampal neurons, mouse cerebellar granule neurons only express $\gamma 2$, which is crucial for AMPA receptor surface expression in these cells (Chen et al., 2000; Tomita et al., 2003). Cultures were prepared from $\mathrm{P} 2$ mouse pups, and recordings were performed at $7 \mathrm{~d}$

in vitro. In this system in which receptors that do not contain $\gamma 2$ do not readily reach the surface, only subtle functional differences were observed with overexpression of $\gamma 2$. Neither normalized steady-state glutamate currents (Fig. 2A,B) nor percentage of desensitization (control, $97.5 \pm$ $0.4 \%$ versus $\gamma 2,96.4 \pm 0.4 \%$; mean \pm SEM; $n=12-14)$ was changed. There was a small $(17 \%)$ but significant increase in relative kainate responses (Fig. $2 A, C$ ). Interestingly, kainate responses in control cerebellar granule cells averaged 50\% larger than peak glutamate currents (Fig. $2 C$ ), a percentage only approached in certain hippocampal neurons with exogenous $\gamma 2$ expression. Thus, endogenous $\gamma 2$ association appears to contribute to the unique functional properties of AMPA receptors in control cerebellar granule cells, such as the much greater relative efficacy of kainate compared with control hippocampal neurons. In contrast to the minimal functional effects in granule cells, $\gamma 2$ overexpression significantly increased current density (Fig. $2 D)$, suggesting that the amount of $\gamma 2$ in granule cells is limiting and overexpression can contribute to increased trafficking of receptors to the cell surface.

\section{Stargazin destabilizes the desensitized state of the AMPA receptor}

To begin to address the mechanism underlying the functional effects of $\gamma 2$ on native AMPA receptors, we first examined the relative increase in kainate efficacy. Overexpression of $\gamma 2$ in hippocampal neurons shifted the kainate dose-response curve to the left approximately threefold (Fig. $3 A$ ). This is similar to the shift produced by the positive modulator cyclothiazide (Patneau et al., 1993) and could reflect decreased receptor desensitization. Alternatively, $\gamma 2$ association could effect a conformational change that directly affects the affinity of kainate, allows greater domain closure after kainate binding, or alters the coupling of domain closure with channel gating. To distinguish between these possibilities, we examined the association and dissociation rates of kainate applied in the presence of glutamate. Because glutamate has a higher affinity for the desensitized state, kainate can only compete glutamate from nondesensitized receptors (Patneau and Mayer, 1991). Thus, this protocol allowed us to assess both the rate of recovery from glutamate-evoked desensitization and the rate of dissociation of kainate. $\gamma 2$ overexpression significantly increased the rate of recovery from glutamateevoked desensitization as determined by faster kainate association (Fig. $3 B, C$ ). However, there was no change in dissociation kinetics (Fig. $3 B, C$ ), indicating that $\gamma 2$ does not alter the affinity of kainate for the receptor.

A faster rate of recovery from desensitization and reduced 

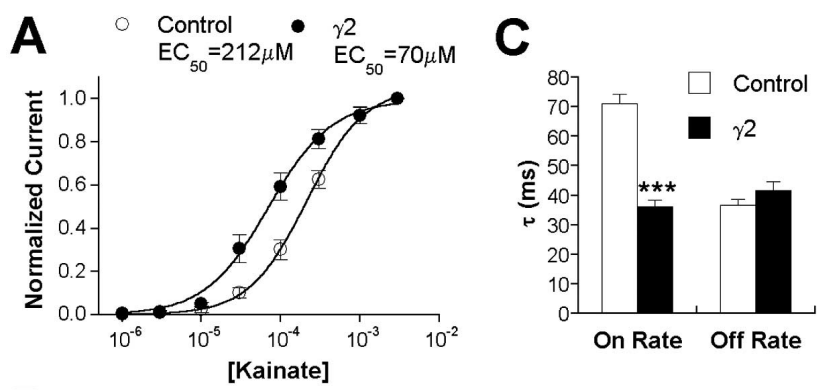

B
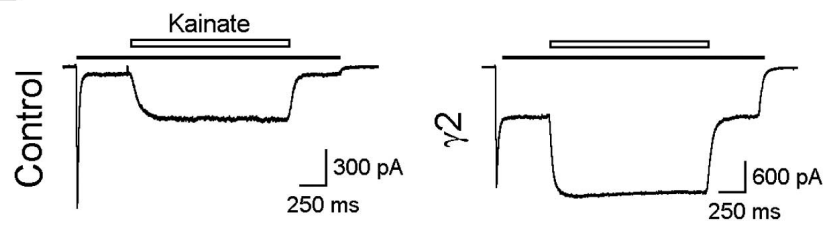

Figure 3. $\quad \gamma 2$ increases kainate efficacy and speeds recovery from desensitization in hippocampal neurons. $A$, Dose-response curves for kainate-evoked currents in hippocampal neurons transfected with GFP (control) or $\gamma 2$ plus GFP. Currents were normalized relative to $3 \mathrm{~mm}$ kainate. Points represent the mean \pm SEM ( $n=4-11$, depending on dose). $\boldsymbol{B}$, Representative traces from neurons transfected with GFP or $\gamma 2$ plus GFP illustrate the association and dissociation of kainate $(600 \mu \mathrm{m})$ in the presence of glutamate $(200 \mu \mathrm{M})$. C, Both association $\left(\tau_{\text {on }}\right)$ and dissociation $\left(\tau_{\text {off }}\right)$ of kainate in the presence of glutamate were well fit by a single exponential function. Error bars represent the mean \pm SEM (control, $n=16 ; \gamma 2, n=15)$. ${ }^{* *} p<0.001$, difference for $\gamma 2$ relative to the respective control.

steady-state desensitization in hippocampal neurons suggests $\gamma 2$ alters the equilibrium between desensitized and nondesensitized states of the receptor. Crystallization of the ligand-binding cores of GluR-B has shown that the interface between two adjacent AMPA receptor subunits is closely apposed in both the resting and open states but separates during the conformational transition to the desensitized state (Sun et al., 2002) and that the positive allosteric modulator cyclothiazide binds at and stabilizes this dimer interface. Implicit in this model is the loss of the binding site for the benzothiadiazines in the desensitized conformation. The limited binding of the benzothiadiazines, including cyclothiazide and TCM, to the desensitized state of the receptor can be demonstrated electrophysiologically by their dramatically slowed association in the presence of strongly desensitizing agonists (Patneau et al., 2002). Therefore, direct information about the conformational state of the receptor can be obtained from the association kinetics of TCM. In hippocampal neurons overexpressing $\gamma 2$, the time constants for the onset of TCM modulation were more than five times faster than in control neurons, consistent with a faster rate of recovery from desensitization (Fig. $4 A, B$ ). The time constant of dissociation was unaffected (Fig. $4 C$ ), indicating that the affinity of TCM for the nondesensitized state is unchanged, and, by implication, that $\gamma 2$ does not substantially alter the conformation of the dimer interface in the open state. These data therefore suggest that $\gamma 2$ association shifts the equilibrium between desensitized and open conformations of the AMPA receptor by destabilizing the desensitized state.

Stargazin affects both trafficking and functional properties of AMPA receptors in heterologous cells

Because both hippocampal and cerebellar granule neurons express heterogeneous receptor populations and have the complication of endogenous TARP expression, we moved to a heterologous expression system to further explore the effects of $\gamma 2$ on
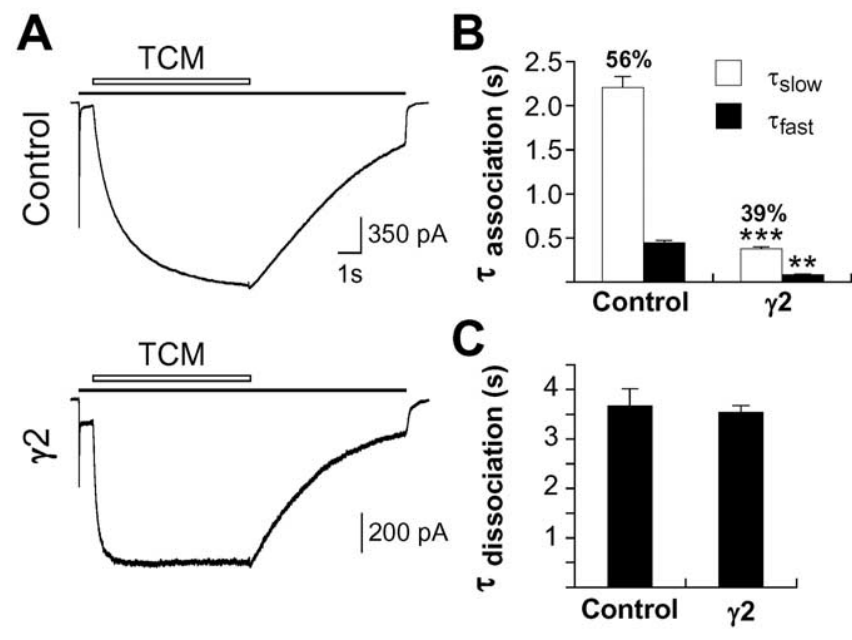

Figure 4. The onset of modulation by TCM is faster in neurons transfected with $\gamma 2$. $A$, Traces from representative hippocampal neurons transfected with GFP or $\gamma 2$ plus GFP show the association and dissociation kinetics of TCM $(500 \mu \mathrm{M})$ in the presence of glutamate (3 mM). Time constants for the onset $(\boldsymbol{B})$ and offset $(\boldsymbol{C})$ of TCM modulation in hippocampal neurons transfected with GFP or $\gamma 2$ are shown. Onset kinetics were fit with the sum of two exponentials (percentage of contribution of $\tau_{\text {slow }}$ is shown), whereas dissociation kinetics were best described by a single exponential. Error bars represent the mean \pm SEM (control, $n=19 ; \gamma 2, n=$ 17). ${ }^{* *} p<0.01,{ }^{* * *} p<0.001$, difference for $\gamma 2$ relative to the respective control.

AMPA receptor function. AMPA receptor subunits occur naturally as one of two alternative isoforms, flip(i) or flop(o), that differ in their desensitization properties (Sommer et al., 1990). AMPA receptors are preferentially assembled as heteromers containing both flip and flop isoforms (Mansour et al., 2001; Brorson et al., 2004). HEK293 cells were therefore cotransfected with GluR- $A_{i}$ and $B_{o}$ to form heteromeric receptors that reproduce some characteristics of native hippocampal AMPA receptors. $\gamma 2$ coexpression had substantially larger effects on kainate efficacy than in hippocampal neurons, with both normalized steady-state glutamate and kainate currents potentiated $\sim 10$-fold over control (Fig. 5A-C). We also observed a pronounced slowing in the rate of glutamate desensitization (control $\tau=4.4 \pm 0.2, n=14$; $\gamma 2 \tau=7.1 \pm 0.5, n=17$; mean \pm SEM; $p<0.001 ; t$ test). Note that relative glutamate and kainate steady-state responses in control HEK293 cells expressing GluR- $\mathrm{A}_{\mathrm{i}} \mathrm{B}_{\mathrm{o}}$ are much smaller ( 1 and $7 \%$ of peak glutamate, respectively) than those of native receptors in hippocampal neurons (Fig. 1). It is intriguing that the characteristics of recombinant receptors coexpressed with $\gamma 2$ more accurately reproduce those observed in native receptors.

In contrast to effects in hippocampal neurons, $\gamma 2$ coexpression increased current density 3.4-fold in HEK293 cells expressing $\mathrm{A}_{\mathrm{i}} \mathrm{B}_{\mathrm{o}}$ heteromers (Fig. $5 D$ ). To corroborate this functional assay for effects on AMPA receptor trafficking, surface biotinylation experiments were performed in sister $A_{i} B_{o}$ cultures. Quantitative Western blots revealed an average 3.2-fold increase in GluR-A and a 2.9-fold increase in GluR-B surface protein with $\gamma 2$ coexpression (Fig. $5 E, F$ ). Thus, the increase in AMPA receptor surface expression can account for the potentiation of glutamate peak responses; however, when this increase in surface expression is factored out, the 10 -fold increase in relative glutamate steady-state responses remains. To determine whether $\gamma 2$ differentially affected flip and flop splice variants, we also examined $\mathrm{A}_{\mathrm{i}} \mathrm{B}_{\mathrm{i}}$ and $\mathrm{A}_{\mathrm{o}} \mathrm{B}_{\mathrm{o}}$ heteromers. Although we observed trafficking and functional effects for all heteromeric combinations, the magnitude of these effects were dependent on receptor composition (Table 1). 
A
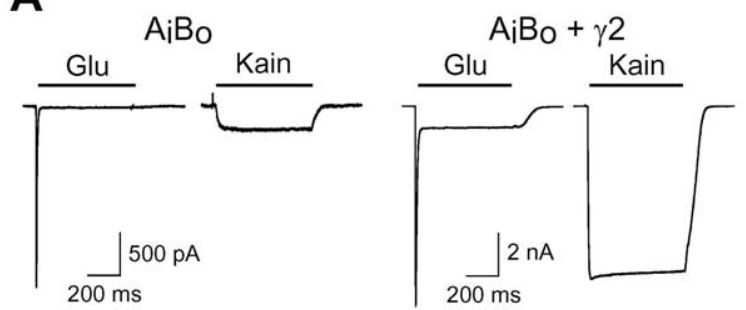

C

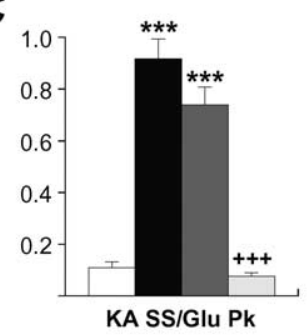

D
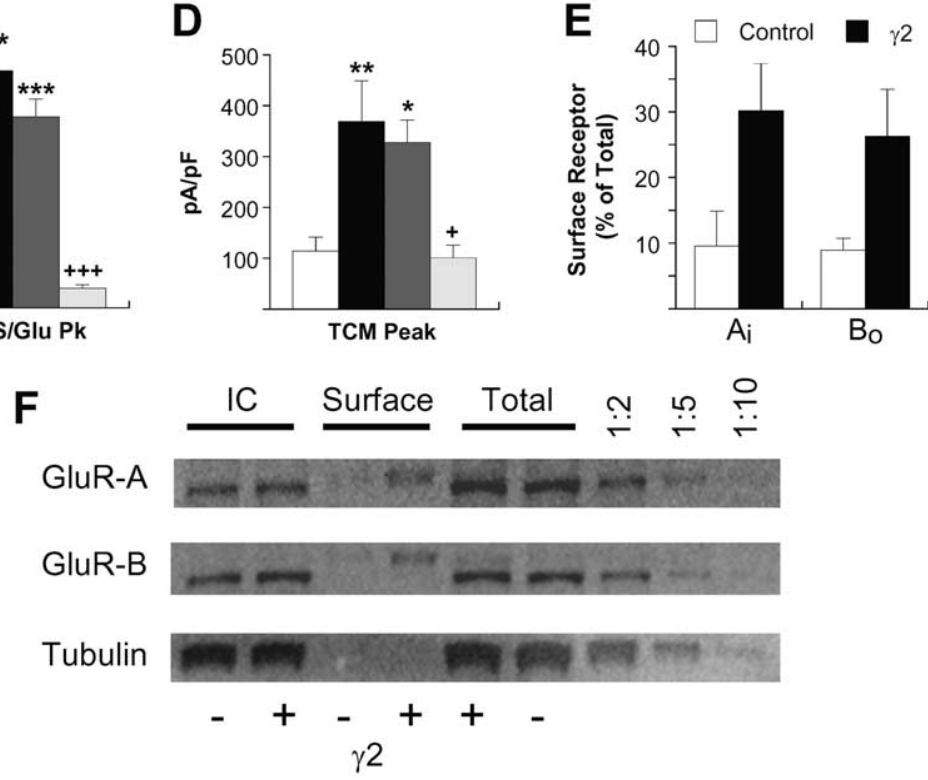

Figure 5. Dissociation of the effects of TARPs on steady-state agonist-evoked currents and AMPA receptor surface expression in heteromeric recombinant receptors. $A$, Responses evoked by glutamate $(3 \mathrm{~mm}$ ) and kainate (Kain; $600 \mu \mathrm{m})$ for representative HEK293 cells expressing heteromeric GluR- $A_{i} B_{0}$ receptors or GluR- $A_{i} B_{0}$ plus $\gamma 2$. Note the different scale bars for control $(500 p A)$ and $\gamma 2(2 \mathrm{nA})$ cells. Steady-state glutamate $(\boldsymbol{B})$ or kainate (KA; $\boldsymbol{C}$ ) currents normalized to peak glutamate responses in HEK293 cells transfected with GluR- $A_{\mathrm{i}} \mathrm{B}_{0}$ alone or GluR- $\mathrm{A}_{\mathrm{i}} \mathrm{B}_{0}$ plus $\gamma 2, \gamma 3$, or $\gamma 5$. $\boldsymbol{D}$, Current density was calculated by normalizing peak glutamate plus TCM responses to whole-cell capacitance. The error bars in $\boldsymbol{B}-\boldsymbol{D}$ represent the mean $\pm \mathrm{SEM}(n=12-17)$. ${ }^{*} p<$ $0.05,{ }^{* *} p<0.01,{ }^{* * *} p<0.001$, significant difference relative to respective control; ${ }^{+} p<0.05,{ }^{++} p<0.01,{ }^{+++} p<$ 0.001 , significant difference from $\gamma 2$. $\boldsymbol{E}$, Surface biotinylation experiments were performed in HEK293 cells transfected with GluR- $A_{i} B_{0}$ alone or GluR- $A_{i} B_{0}$ plus $\gamma 2$. Mean data from surface biotinylation of three independent transfections \pm SEM are shown. $\boldsymbol{F}$, Western blots from a single experiment probed with antibodies for GluR-A or GluR-B. The GluR-B blot was reprobed with tubulin as a control. The three lanes on the right are 1:2, 1:5, and 1:10 dilutions of the GluR- $A_{i} B_{0}$ total protein sample. Glu, Glutamate; $C$ on, control; SS, steady state; Pk, peak; IC, intracellular.

Three calcium channel $\gamma$ subunit family members closely related to stargazin, $\gamma 3, \gamma 4$, and $\gamma 8$, have also been identified as TARPs based on their ability to restore AMPA receptor-mediated currents in stargazer cerebellar granule cells, whereas the more distantly related family members $\gamma 1, \gamma 5, \gamma 6$, and $\gamma 7$ cannot (Tomita et al., 2003). To determine whether other TARPs share the functional effects of $\gamma 2$, HEK293 cells were cotransfected with $\mathrm{A}_{\mathrm{i}} \mathrm{B}_{\mathrm{o}}$ and $\gamma 3$ or $\gamma 5$. $\gamma 3$ potentiated both steady-state glutamate and kainate currents, whereas $\gamma 5$ had no significant effect on receptor function (Fig. $5 B, C$ ). Similar results were obtained with $\gamma 3$ and $\gamma 5$ in hippocampal neurons (data not shown). $\gamma 3$, but not $\gamma 5$, also significantly increased current density in HEK293 cells expressing $\mathrm{A}_{\mathrm{i}} \mathrm{B}_{\mathrm{o}}$ heteromers (Fig. $5 D$ ). It is particularly interesting that although $\gamma 3$ significantly decreased receptor desensitization, the effect was only half that observed with $\gamma 2$, indicating that various TARPs may differentially associate and/or have different functional effects with a given AMPA receptor subtype.
Stargazin differentially affects individual AMPA receptor subunits To rule out the possibility that $\gamma 2$ affected AMPA receptor functional properties by altering subunit composition in native or heteromeric recombinant receptors, we also examined the effects of $\gamma 2$ expression on homomeric GluR- $\mathrm{A}_{\mathrm{i}}, \mathrm{B}_{\mathrm{i}}, \mathrm{C}_{\mathrm{i}}$, and $\mathrm{D}_{\mathrm{i}}$ receptors. In HEK293 cells expressing GluR-A homomers, $\gamma 2$ coexpression potentiated normalized steady-state glutamate (3.3-fold) and kainate (37-fold) currents (Fig. 6A,C,D), while increasing current density threefold (Fig. 6E). Although $\gamma 2$ significantly altered functional properties of all four homomers, subunitspecific effects were apparent. Most strikingly, effects of $\gamma 2$ on kainate and glutamate steady-state were similar for GluR-B $B_{i}$ (Fig. 6A-D), whereas kainate responses were much more strongly affected in the other three subunits (Table 2). The functional effects of $\gamma 3$ also differed between subunits, with effects on GluR- $B_{i}$ homomers more closely resembling those seen in GluR- $\mathrm{A}_{\mathrm{i}} \mathrm{B}_{\mathrm{o}}$ heteromers (compare Figs. $5 B, C, 6 C, D)$. As expected, $\gamma 5$ had no functional or trafficking effects on GluR- $\mathrm{A}_{\mathrm{i}}$ or $\mathrm{B}_{\mathrm{i}} \cdot \gamma 2$ also exhibited differential trafficking effects, producing severalfold increases in current density for GluR-A, B, and D and having no significant effect on GluR-C (Table 2). Together, these results suggest that the functional effects of $\gamma 2$ are mediated by association at the cell surface rather than by effects on receptor assembly.

The effect of $\gamma 2$ on peak glutamateevoked currents in GluR- $\mathrm{A}_{\mathrm{i}}$ homomers was voltage dependent, with coexpression resulting in significantly less inward current at holding potentials of $-80 \mathrm{mV}$ or less and significantly more outward current at potentials of $+80 \mathrm{mV}$ or greater (normalized relative to $-60 \mathrm{mV}$ ) (Fig. $6 \mathrm{~F}$ ). We also observed a significant increase in outward rectification for GluR-D $D_{\mathrm{i}}$ (data not shown). Given the voltage dependence of AMPA receptor gating and/or desensitization (Patneau et al., 1993; Raman and Trussell, 1995), it is unclear whether this reflects an additional effect of $\gamma 2$ on channel function or is a consequence of changes in other voltage-dependent channel properties.

Because binding of $\gamma 2$ to PSD-95 via its C-terminal PDZ (PSD-95/Discs large/zona occludens-1)-binding motif is important for synaptic delivery of AMPA receptors (Chen et al., 2000), we examined coexpression of PSD-95 on the functional effects of $\gamma 2$ in homomeric GluR-A $A_{i}$ receptors. The effects of $\gamma 2 /$ PSD-95 coexpression were statistically indistinguishable from $\gamma 2$ alone for normalized glutamate (Fig. 7A) and kainate steady-state currents $(B)$ as well as whole-cell current density $(C)$. Although the effects of $\gamma 2$ relative to control on glutamate steady-state did not reach significance for this subset of experiments (Fig. 7A), we nonetheless observed a significant slowing of the onset of desensitization in the presence of $\gamma 2$, which was independent of 
Table 1. Effects of $\gamma 2$ coexpression on heteromeric AMPA receptors in heterologous cells

\begin{tabular}{|c|c|c|c|c|c|c|c|}
\hline & & Glu Pk (pA) & Glu SS (pA) & KASS (pA) & KA/Glu Pk (\%) & $\begin{array}{l}\text { TPk/WCC } \\
(\mathrm{pA} / \mathrm{pF})\end{array}$ & $\begin{array}{l}\text { Desensitization } \\
(\%)\end{array}$ \\
\hline \multirow[t]{2}{*}{$\mathrm{A}_{\mathrm{i}} \mathrm{B}_{0}(n=15-17)$} & Con & $745 \pm 168$ & $6 \pm 1$ & $55 \pm 12$ & $11 \pm 2$ & $114 \pm 27$ & $99.4 \pm 0.2$ \\
\hline & $\gamma 2$ & $4242 \pm 646^{* * *}$ & $550 \pm 107^{* * *}$ & $3625 \pm 516^{* * *}$ & $92 \pm 8^{* * *}$ & $350 \pm 65^{* *}$ & $89.3 \pm 1.7^{* * *}$ \\
\hline \multirow[t]{2}{*}{$\mathrm{A}_{\mathrm{i}} \mathrm{B}_{\mathrm{i}}(n=12-14)$} & Con & $1349 \pm 442$ & $64 \pm 19$ & $147 \pm 48$ & $12 \pm 1$ & $195 \pm 48$ & $97.7 \pm 0.4$ \\
\hline & $\gamma 2$ & $3894 \pm 592^{* *}$ & $989 \pm 174^{* * *}$ & $2398 \pm 426^{* * *}$ & $61 \pm 6^{* * *}$ & $414 \pm 66^{*}$ & $84.0 \pm 3.0^{* * *}$ \\
\hline \multirow[t]{2}{*}{$A_{0} B_{0}(n=10-14)$} & Con & $165 \pm 48$ & $3 \pm 1$ & $56 \pm 15$ & $35 \pm 5$ & $22 \pm 5$ & $99.3 \pm 0.1$ \\
\hline & $\gamma 2$ & $1843 \pm 339^{* * *}$ & $205 \pm 53^{* *}$ & $3079 \pm 537^{* * *}$ & $170 \pm 11^{* * *}$ & $214 \pm 42^{* *}$ & $93.4 \pm 1.1^{* * *}$ \\
\hline
\end{tabular}

HEK293 cells were transfected with the AMPA receptor combinations shown with or without $\gamma 2$ coexpression. Relative kainate (KA) efficacy is expressed as a percentage of the peak (Pk) response to 3 mm glutamate (Glu). Current density as an assay for surface receptor expression, was determined by normalizing Glu plus TCM peak to whole-cell capacitance (TPk/WCC). Desensitization was calculated relative to maximal currents in the presence of TCM (\% desensitization = $[1-($ Glu SS/Glu + TCM peak) $] \times 100)$. The $\gamma 2$ condition was significantly different from receptor alone $\left({ }^{*} p<0.05 ;{ }^{* *} p<0.05 ;{ }^{* * *} p<0.001 ; t\right.$ test). SS, Steady state; Con, control.

PSD-95 expression (Fig. 7D). As expected, PSD-95 coexpression alone did not alter either the functional properties or levels of surface expression for GluR- $\mathrm{A}_{\mathrm{i}}$ receptors. Thus, PSD-95 is not necessary for, and does not significantly alter, the functional effects of $\gamma 2$ on AMPA receptors.

Extracellular and intracellular domains of stargazin differentially mediate trafficking and functional effects

Tomita et al. (2004) demonstrated that two regions in $\gamma 2$, an area in the first extracellular loop and a proximal region in the cytoplasmic tail, mediated association with GluR-B and were necessary for GluR-A trafficking in Xenopus oocytes. It was therefore of interest whether these same regions mediated the functional effects of $\gamma 2$. We first generated a series of $\gamma 2$ C-terminal truncations: $\gamma 2(1-212)$ was truncated 10 aa after the fourth transmembrane domain and lacks most of the cytoplasmic tail, whereas the $\gamma 2(1-244)$ and $\gamma 2(1-288)$ truncations were spaced evenly throughout the remainder of the tail (Fig. $8 A)$. Both $\gamma 2(1-212)$ and $\gamma 2(1-244)$ produced a significant decrement in current density relative to the effect of $\gamma 2$ on GluR$A_{i}$, whereas the effects of $\gamma 2(1-288)$ were indistinguishable from full-length $\gamma 2$ (Fig. $8 B)$. These data suggest that, in agreement with Tomita et al. (2004), a region between amino acids 212 and 288 in the $\gamma 2$ cytoplasmic tail is the major mediator of AMPA receptor trafficking.

Interestingly, the cytoplasmic tail was also critical for the effects of $\gamma 2$ on desensitization, with deletion of amino acids 213323 of $\gamma 2$ abolishing potentiation of glutamate-evoked, steadystate responses for GluR- $\mathrm{A}_{\mathrm{i}}[\gamma 2(1-212)]$ (Fig. 8C). In contrast to our observations with trafficking, $\gamma 2(1-288)$ was unable to duplicate the effects of full-length $\gamma 2$, suggesting that residues throughout the $\mathrm{C}$ terminus may contribute to a tertiary structure necessary for the effect of $\gamma 2$ on receptor desensitization. Kainate-evoked currents in cells coexpressing $\gamma 2(1-212)$ or $\gamma 2(1-244)$ were significantly potentiated over controls but reduced relative to $\gamma 2$, whereas $\gamma 2(1-288)$ was indistinguishable from full-length $\gamma 2$ (Fig. $8 D$ ). Although these data suggest that residues $212-288$ contribute to the shift in kainate efficacy, the 13-fold increase in relative kainate currents retained by $\gamma 2(1-$ 212) indicates that other regions are important for this effect of $\gamma 2$. It is interesting that $\gamma 3$, which shares substantial homology ( $84 \%$ amino acid identity) with $\gamma 2$ through the end of the fourth transmembrane region but has greater divergence (56\% identity) in the $\mathrm{C}$ terminus, has effects on both trafficking and AMPA receptor function that were statistically indistinguishable from those of $\gamma 2(1-$ 212) $(p>0.89)$.

To examine the role of the first extracellular loop in the functional effects of $\gamma 2$, we constructed a $\gamma 2 / \gamma 5$ chimera, $\gamma 2(\Delta 26-$ $103) / \gamma 5$ (ins 26-99), that replaced this region of $\gamma 2$ with the corresponding sequence from $\gamma 5$, a TARP that has no significant effects on AMPA receptor trafficking or function (Fig. $8 \mathrm{~A}$ ). Coexpressing $\gamma 2(\Delta 26-103) / \gamma 5$ (ins $26-99)$ with GluR-A $A_{i}$ homomeric receptors produced effects that were almost the inverse of 
Table 2. Effects of $\gamma 2$ coexpression on homomeric AMPA receptors in heterologous cells

\begin{tabular}{|c|c|c|c|c|c|c|c|}
\hline & & Glu Pk (pA) & Glu SS (pA) & KASS (pA) & $\begin{array}{l}\text { KA/Glu Pk } \\
(\%)\end{array}$ & $\begin{array}{l}\text { TPk/WCC } \\
(\mathrm{pA} / \mathrm{pF})\end{array}$ & $\begin{array}{l}\text { Desensitization } \\
(\%)\end{array}$ \\
\hline \multirow[t]{2}{*}{$A_{i}(n=42-62)$} & Con & $739 \pm 124$ & $9 \pm 2$ & $9 \pm 1$ & $3 \pm 1$ & $173 \pm 23$ & $99.6 \pm 0.1$ \\
\hline & $\gamma 2$ & $5530 \pm 421^{* * *}$ & $350 \pm 52^{* * *}$ & $5682 \pm 409^{* * *}$ & $112 \pm 4^{* * *}$ & $621 \pm 42^{* * *}$ & $96.3 \pm 0.7^{* * *}$ \\
\hline \multirow[t]{2}{*}{$\mathrm{B}_{\mathrm{i}}(n=18)$} & Con & $78 \pm 13$ & $9 \pm 2$ & $7 \pm 1$ & $8 \pm 1$ & $11 \pm 2$ & $96.4 \pm 0.4$ \\
\hline & $\gamma 2$ & $1837 \pm 298^{* * *}$ & $1090 \pm 220^{* * *}$ & $1070 \pm 219^{* * *}$ & $55 \pm 3^{* * *}$ & $134 \pm 20^{* * *}$ & $47.0 \pm 5.0^{* * *}$ \\
\hline \multirow[t]{2}{*}{$C_{i}(n=12-13)$} & Con & $324 \pm 57$ & $4 \pm 1$ & $19 \pm 5$ & $6 \pm 1$ & $80 \pm 14$ & $99.7 \pm 0.1$ \\
\hline & $\gamma 2$ & $726 \pm 269$ & $40 \pm 21$ & $973 \pm 335^{*}$ & $138 \pm 7^{* * *}$ & $102 \pm 24$ & $98.5 \pm 0.2^{* * *}$ \\
\hline \multirow[t]{2}{*}{$D_{i}(n=17-20)$} & Con & $1995 \pm 347$ & $100 \pm 37$ & $48 \pm 19$ & $2 \pm 0.4$ & $354 \pm 51$ & $98.6 \pm 0.4$ \\
\hline & $\gamma 2$ & $6924 \pm 458^{* * *}$ & $786 \pm 148^{* * *}$ & $4926 \pm 648^{* * *}$ & $70 \pm 8^{* * *}$ & $728 \pm 63^{* * *}$ & $92.2 \pm 1.8^{* *}$ \\
\hline
\end{tabular}

HEK293 cells were transfected with GluR-A,-B, -C, or -D flip isoforms with or without $\gamma 2$ coexpression. Relative kainate (KA) efficacy is expressed as a percentage of the peak (Pk) response to 3 mm glutamate (Glu). Current density, as an assay for surface receptor expression, was determined by normalizing Glu plus TCM peak to whole-cell capacitance (TPk/WCC). Desensitization was calculated relative to maximal currents in the presence of TCM (\% desensitization $=[1-$ (Glu SS/Glu + TCM peak) $] \times 100)$. The $\gamma 2$ condition is significantly different from receptor alone $\left({ }^{*} p<0.05 ;{ }^{* *} p<0.01 ;{ }^{* * *} p<0.001 ; t\right.$ test). SS, Steady state; Con, control.
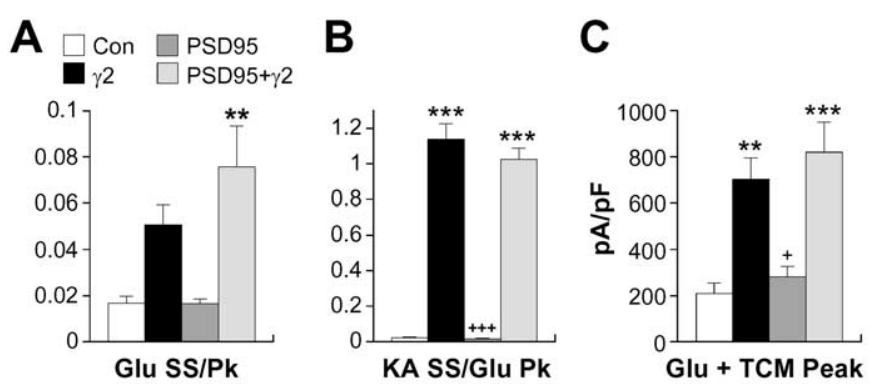

Figure 7. PSD-95 coexpression does not alter the effects of $\gamma 2$ on AMPA receptor functional properties. Normalized glutamate $(\boldsymbol{A})$ and kainate $(K A ; B)$ steady-state currents in HEK293 cells transfected with GluR- $A_{i}$ alone or with $\gamma 2$, PSD-95, or both PSD-95 and $\gamma 2$ are shown. $C$, Current density was determined by normalizing peak glutamate plus TCM responses to whole-cell capacitance. $\boldsymbol{D}$, Time constants determined by single-exponential fits to the onset of desensitization for glutamate-evoked responses in HEK cells expressing GluR-A alone or with $\gamma 2$, PSD-95, or both PSD-95 and $\gamma 2$. The error bars in $\boldsymbol{A}-\boldsymbol{D}$ represent the mean \pm SEM $(n=11-19) .{ }^{* *} p<0.01,{ }^{* * *} p<0.001$, significant difference relative to the corresponding control; ${ }^{+} p<0.05,{ }^{+++} p<$ 0.001 , significant difference from $\gamma 2$ condition. Glu, Glutamate; Con, control; SS, steady state; Pk, peak.

those observed with $\gamma 2(1-212)$. Although current density was unaffected relative to $\gamma 2$ (Fig. $8 \mathrm{~B}$ ), the shift in kainate efficacy was totally eliminated $(D)$. Whereas normalized steady-state glutamate responses in cells coexpressing $\gamma 2(\Delta 26-103) / \gamma 5$ (ins $26-99)$ were approximately one-half of those observed with $\gamma 2$, they were not significantly different from either $\gamma 2$ or control (Fig. $8 C)$. A second $\gamma 2 / \gamma 5$ chimera, $\gamma 2(\Delta 89-103) / \gamma 5$ (ins $85-99)$, which exchanged only 15 aa just before TM2, was statistically indistinguishable from $\gamma 2$ on steady-state, glutamate-evoked current but still showed a significant decrement in the shift of kainate efficacy (Fig. $8 C, D$ ). Together, these data suggest that functional effects are mediated by multiple regions on $\gamma 2$. Although both the intracellular C-terminal domain and first extracellular loop of $\gamma 2$ seem to contribute to each functional effect, the cytoplasmic tail plays a larger role in reducing glutamate steady-state desensitization, and the first extracellular loop plays a larger role in increasing kainate efficacy.

\section{Discussion}

The data presented here provide evidence that stargazin alters the biophysical properties of native AMPA receptors in two distinct ways, one resulting in decreased receptor desensitization and the other resulting in increased kainate efficacy. This confirms and extends results from two recent studies reporting that stargazin enhances glutamate-evoked currents in HEK293 cells expressing homomeric GluR-A $\mathrm{i}_{\mathrm{i}}$ or GluR-B $\mathrm{B}_{\mathrm{i}}$ receptors (Yamazaki et al., 2004) by reducing receptor desensitization (Priel et al., 2005). Although
D

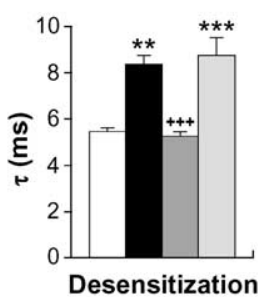

robust levels of functional AMPA receptors observed in heterologous systems demonstrate that association with TARPs is not obligatory for AMPA receptor surface expression, TARP coexpression clearly results in more efficient trafficking of receptors. A recent paper (Nakagawa et al., 2005) suggested that most, if not all, neuronal AMPA receptors are associated with TARPs. Our functional assay indicates that surface AMPA receptors in cerebellar granule cells already contain saturating levels of $\gamma 2$, but receptors in $\mathrm{P} 7$ hippocampal neurons can accommodate additional $\gamma 2$ association. Although this could reflect that few hippocampal AMPA receptors are associated with TARPs, the lack of increased surface expression in $\gamma 2$ transfected hippocampal neurons suggests instead that receptor trafficking is already saturated by other endogenous TARPs and that stargazin alters receptor functional properties by substituting for endogenous TARPs that are equally efficacious in trafficking but have different functional effects. Our observation that individual subunits are differentially modulated by stargazin and $\gamma 3$ supports this hypothesis. It is clear that TARPs must now be considered as a factor contributing to AMPA receptor functional heterogeneity.

Based on recordings from Xenopus oocytes, Tomita et al. (2004) found that both the first extracellular domain of stargazin and a region in the cytoplasmic tail were necessary for increasing AMPA receptor currents, a finding interpreted as being exclusively attributable to trafficking. Using whole-cell current density as a measure of total cell-surface receptors, we found that increased receptor surface expression was mediated primarily by the C-terminal intracellular domain of stargazin. In contrast, both the first extracellular domain and the C-terminal tail were required for stargazin to exert maximal functional effects on AMPA receptors. However, the decrease in receptor desensitization and the increase in kainate efficacy can be partially dissociated, with the former being more dependent on the cytoplasmic tail and the latter being more dependent on a functional first extracellular loop. Our observation of almost complete loss of the effect of $\gamma 2$ on glutamate-evoked desensitization with a truncation at amino acid 212, and the inability of more limited truncations to fully rescue this deficit, indicates that an intact $\gamma 2$ C-terminal tail is important for modulating steady-state AMPA 

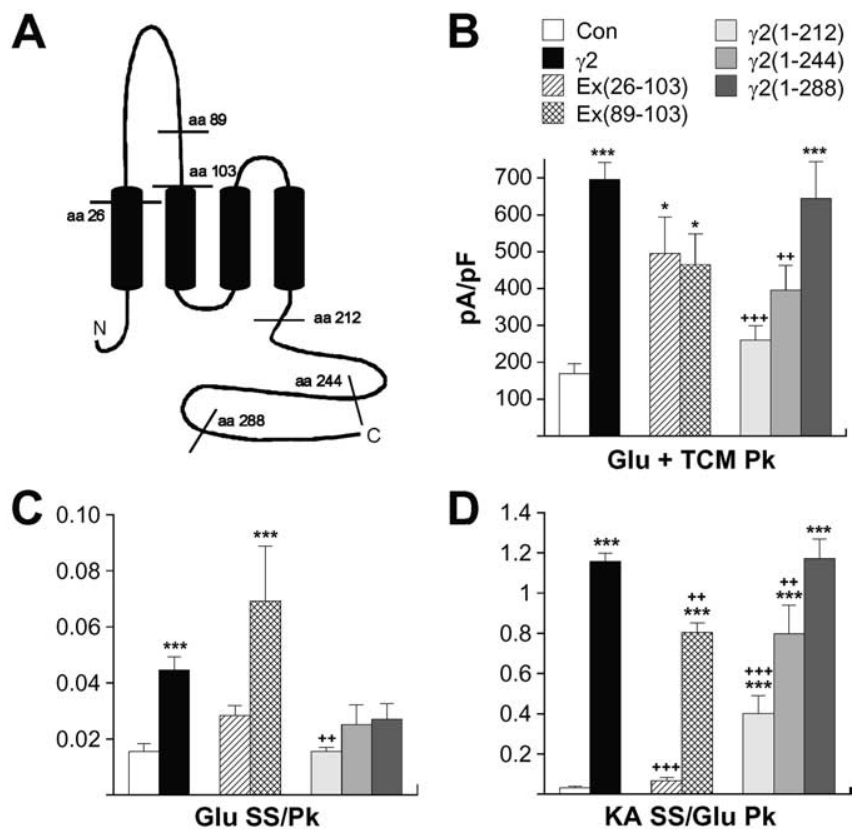

Figure 8. Both intracellular and extracellular regions of $\gamma 2$ mediate functional changes in AMPA receptor properties. $\boldsymbol{A}$, Schematic depiction of the transmembrane topology of $\gamma 2$. Amino acids demarcating boundaries for the chimeras and the C-terminal truncations are noted. Current density $(\boldsymbol{B})$, normalized glutamate steady-state currents $(\boldsymbol{C})$, and normalized kainate currents (KA; $\boldsymbol{D})$ in HEK293 cells transfected with GluR-A alone or GluR- $A_{i}$ plus $\gamma 2$, $\gamma 2(\Delta 26-103) / \gamma 5$ (ins26-99), $\gamma 2(\Delta 89-103) / \gamma 5$ (ins85-99), $\gamma 2(1-212), \gamma 2(1-244)$, or $\gamma 2(1-288)$ are shown. The error bars in $\boldsymbol{B}-\boldsymbol{D}$ represent the mean \pm SEM $(n=9-46) .{ }^{*} p<$ $0.05,{ }^{* *} p<0.01,{ }^{* * *} p<0.001$, significant difference relative to the corresponding control; ${ }^{+} p<0.05,{ }^{++} p<0.01,{ }^{++}{ }^{+} p<0.001$, significant difference from $\gamma 2$ condition. Glu, Glutamate; Con, control; SS, steady state; Pk, peak.

receptor desensitization. Conversely, our observation that exchange of 15 aa of the $\gamma 2$ sequence immediately before TM2 significantly reduces kainate efficacy by $\sim 30 \%$, but has no effect on the decrease in desensitization, indicates that interactions between the extracellular domains of stargazin and the AMPA receptor mediate increased kainate efficacy. The physical dissociation of regions important for the two principal functional effects of stargazin suggests they are mediated by distinct local conformational changes in the AMPA receptor protein.

The decrease in macroscopic glutamate-evoked desensitization observed with $\gamma 2$ coexpression indicates that $\gamma 2$ shifts the equilibrium between desensitized and open conformations of the AMPA receptor toward open states. This could be achieved either by stabilizing the dimer interface, and thus hindering the transition into the desensitized state, or by destabilizing the desensitized conformation so that the receptor more readily cycles back to an open state. Based on reduced potentiation of glutamateevoked currents by cyclothiazide in the presence of $\gamma 2$, Priel et al. (2005) suggested that, similar to cyclothiazide, $\gamma 2$ affects desensitization by stabilizing the dimer interface. Although the observation that $\gamma 2$ slows the onset of desensitization is consistent with stabilization of the dimer interface, it can also result from the slowed rate of deactivation documented by Priel et al. (2005). The speeding of both kainate and TCM association rates in the presence of glutamate, without a change in affinity for TCM, suggests rather that $\gamma 2$ primarily affects microscopic receptor desensitization by destabilizing the desensitized state. Although numerous manipulations have been described that alter the stability of the dimer interface and thus the stability of the open state (Stern-Bach et al., 1998; Sun et al., 2002; Horning and Mayer, 2004), our results with stargazin indicate equal consideration should be given to interactions that alter the stability of the desensitized state.

The observed increase in kainate efficacy also suggests $\gamma 2$ association induces specific conformational changes in the receptor protein. Rosenmund et al. (1998) demonstrated that sequential binding of agonist to single AMPA receptor channels elicits three unique subconductance states; however, the precise mechanism by which agonist-induced conformational changes in the extracellular ligand binding domains are coupled to various conductance states is not known. Partial agonists induce a lesser degree of domain closure between the D1 and D2 domains in the GluR2 crystal structure than do full agonists, and the amount of closure has been correlated with an agonist-specific profile of subconductance states (Armstrong et al., 2003; Jin et al., 2003). A binding site mutation, GluR2 L650T, that allows kainate to induce greater domain closure increases kainate efficacy and shifts the dose-response curve approximately threefold to the left (Armstrong et al., 2003), which is very similar to the effect we see with $\gamma 2$. It is also possible that rather than affecting the degree of domain closure, $\gamma 2$ alters the efficacy by which the same amount of domain closure is coupled to channel opening. Either mechanism would be predicted to result in a change in the distribution of subconductance states, with more frequent or longer higherconductance openings with kainate bound.

The recent finding that $\gamma 2$ acts as an AMPA receptor-specific chaperone in the endoplasmic reticulum (Vandenberghe et al., $2005 \mathrm{~b}$ ) places it in an ideal location to affect AMPA receptor subunit assembly. However, the fact that we observe decreased desensitization and increased kainate efficacy in homomeric receptors expressed in HEK293 cells suggests that, rather than altering subunit composition, $\gamma 2$ affects AMPA receptor functional properties via a direct interaction with the receptor on the cell surface. Differences in trafficking of individual homomeric receptors does, however, suggest that $\gamma 2$ may preferentially traffic native receptors of certain subunit combinations and also that individual members of the TARP family may participate in guiding assembly of specific AMPA receptor compositions in different cell types.

TARPs have been shown previously to affect the number of receptors at the synapse via association with PSD-95 (Chen et al., 2000; Schnell et al., 2002), and a recent study provides evidence that phosphorylation of $\gamma 2$ may play a role in bidirectional synaptic plasticity (Tomita et al., 2005a). Our data and that of Priel et al. (2005) indicate that TARPs may also affect synaptic strength by changing the biophysical properties of the receptor. The contribution of glutamate deactivation versus desensitization to synaptic responses varies with receptor type, quantal content, and structure of the synapse (Trussell et al., 1993; Kinney et al., 1997; Conti and Weinberg, 1999; Wall et al., 2002; Lawrence et al., 2003). Slowed deactivation would be expected to prolong the time course of most synaptic responses. In contrast, reduced desensitization and altered kinetics of desensitization will have the greatest impact at synapses with high-frequency or prolonged activation (Trussell et al., 1993; Otis et al., 1996; Eliasof and Jahr, 1997). The substantial effects of stargazin on steady-state glutamate responses additionally suggest that TARP association may influence pathological events. AMPA receptors associated with TARPs will be less desensitized by glutamate accumulation in the extracellular space and may make a greater contribution to excitotoxic damage in ischemia.

Our data add to the already strong argument for designation of TARPs as auxiliary AMPA receptor subunits. Three criteria have typically been considered as evidence that a protein acts as 
an ion channel auxiliary subunit: 1) demonstration of a direct and stable interaction with the pore-forming subunit; 2) direct modulation of the biophysical properties; and 3) trafficking of the pore-forming subunit (Arikkath and Campbell, 2003). In addition to the considerable literature documenting the role of stargazin in AMPA receptor trafficking (Chen et al., 2000; Schnell et al., 2002; Cuadra et al., 2004; Vandenberghe et al., 2005b), two recent studies reported the copurification of TARPs with native AMPA receptors (Nakagawa et al., 2005; Vandenberghe et al., 2005a). The observation that $\gamma 2$ alters AMPA receptor channel properties in hippocampal neurons completes the criteria.

Differences in the biophysical characteristics of native AMPA receptors, including desensitization and deactivation, have primarily been attributed to differences in subunit and isoform composition. Our data indicate that association with TARPs provides an additional mechanism controlling channel properties. Whether TARPs are present and which TARPs are included in a receptor are both expected to make significant contributions to the functional heterogeneity of neuronal AMPA receptors.

Note added in proof. While this paper was under review, a report by Tomita et al. (2005b) appeared that shares some of our findings and demonstrates that stargazin alters single-channel conductance by increasing the frequency of large conductance openings.

\section{References}

Arikkath J, Campbell KP (2003) Auxiliary subunits: essential components of the voltage-gated calcium channel complex. Curr Opin Neurobiol 13:298-307.

Armstrong N, Mayer M, Gouaux E (2003) Tuning activation of the AMPAsensitive GluR2 ion channel by genetic adjustment of agonist-induced conformational changes. Proc Natl Acad Sci USA 100:5736-5741.

Bito H, Furuyashiki T, Ishihara H, Shibasaki Y, Ohashi K, Mizuno K, Maekawa M, Ishizaki T, Narumiya S (2000) A critical role for a Rhoassociated kinase, p160ROCK, in determining axon outgrowth in mammalian CNS neurons. Neuron 26:431-441.

Boulter J, Hollmann M, O’Shea-Greenfield A, Hartley M, Deneris E, Maron C, Heinemann S (1990) Molecular cloning and functional expression of glutamate receptor subunit genes. Science 249:1033-1037.

Bredt DS, Nicoll RA (2003) AMPA receptor trafficking at excitatory synapses. Neuron 40:361-379.

Brorson JR, Li D, Suzuki T (2004) Selective expression of heteromeric AMPA receptors driven by flip-flop differences. J Neurosci 24:3461-3470.

Chen L, Chetkovich DM, Petralia RS, Sweeney NT, Kawasaki Y, Wenthold RJ, Bredt DS, Nicoll RA (2000) Stargazin regulates synaptic targeting of AMPA receptors by two distinct mechanisms. Nature 408:936-943.

Conti F, Weinberg RJ (1999) Shaping excitation at glutamatergic synapses. Trends Neurosci 22:451-458.

Cuadra AE, Kuo SH, Kawasaki Y, Bredt DS, Chetkovich DM (2004) AMPA receptor synaptic targeting regulated by stargazin interactions with the Golgi-resident PDZ protein nPIST. J Neurosci 24:7491-7502.

Eliasof S, Jahr CE (1997) Rapid AMPA receptor desensitization in catfish cone horizontal cells. Vis Neurosci 14:13-18.

Garcia EP, Mehta S, Blair LA, Wells DG, Shang J, Fukushima T, Fallon JR, Garner CC, Marshall J (1998) SAP90 binds and clusters kainate receptors causing incomplete desensitization. Neuron 21:727-739.

Hashimoto K, Fukaya M, Qiao X, Sakimura K, Watanabe M, Kano M (1999) Impairment of AMPA receptor function in cerebellar granule cells of ataxic mutant mouse stargazer. J Neurosci 19:6027-6036.

Hollmann M, Hartley M, Heinemann S (1991) $\mathrm{Ca}^{2+}$ permeability of KAAMPA-gated glutamate receptor channels depends on subunit composition. Science 252:851-853.

Horning MS, Mayer ML (2004) Regulation of AMPA receptor gating by ligand binding core dimers. Neuron 41:379-388.

Ihle EC, Patneau DK (2000) Modulation of alpha-amino-3-hydroxy-5methyl-4-isoxazolepropionic acid receptor desensitization by extracellular protons. Mol Pharmacol 58:1204-1212.

Jin R, Banke TG, Mayer ML, Traynelis SF, Gouaux E (2003) Structural basis for partial agonist action at ionotropic glutamate receptors. Nat Neurosci 6:803-810.

Keinanen K, Wisden W, Sommer B, Werner P, Herb A, Verdoorn TA, Sakmann B, Seeburg PH (1990) A family of AMPA-selective glutamate receptors. Science 249:556-560.

Kinney GA, Overstreet LS, Slater NT (1997) Prolonged physiological entrapment of glutamate in the synaptic cleft of cerebellar unipolar brush cells. J Neurophysiol 78:1320-1333.

Lawrence JJ, Brenowitz S, Trussell LO (2003) The mechanism of action of aniracetam at synaptic alpha-amino-3-hydroxy-5-methyl-4isoxazolepropionic acid (AMPA) receptors: indirect and direct effects on desensitization. Mol Pharmacol 64:269-278.

Letts VA, Felix R, Biddlecome GH, Arikkath J, Mahaffey CL, Valenzuela A, Bartlett II FS, Mori Y, Campbell KP, Frankel WN (1998) The mouse stargazer gene encodes a neuronal $\mathrm{Ca}^{2+}$-channel gamma subunit. Nat Genet 19:340-347.

Lin Y, Skeberdis VA, Francesconi A, Bennett MV, Zukin RS (2004) Postsynaptic density protein-95 regulates NMDA channel gating and surface expression. J Neurosci 24:10138-10148.

Mammen AL, Huganir RL, O’Brien RJ (1997) Redistribution and stabilization of cell surface glutamate receptors during synapse formation. J Neurosci 17:7351-7358.

Mansour M, Nagarajan N, Nehring RB, Clements JD, Rosenmund C (2001) Heteromeric AMPA receptors assemble with a preferred subunit stoichiometry and spatial arrangement. Neuron 32:841-853.

Nakagawa T, Cheng Y, Ramm E, Sheng M, Walz T (2005) Structure and different conformational states of native AMPA receptor complexes. Nature 433:545-549.

Otis TS, Wu YC, Trussell LO (1996) Delayed clearance of transmitter and the role of glutamate transporters at synapses with multiple release sites. J Neurosci 16:1634-1644.

Patneau DK, Mayer ML (1991) Kinetic analysis of interactions between kainate and AMPA: evidence for activation of a single receptor in mouse hippocampal neurons. Neuron 6:785-798.

Patneau DK, Vyklicky Jr L, Mayer ML (1993) Hippocampal neurons exhibit cyclothiazide-sensitive rapidly desensitizing responses to kainate. J Neurosci 13:3496-3509.

Patneau DK, Garringer E, Gulick MA, Urick K (2002) Benzothiadiazine and benzodiazepine modulators compete for different states of the AMPA receptor. Soc Neurosci Abstr 28:540.6.

Priel A, Kolleker A, Ayalon G, Gillor M, Osten P, Stern-Bach Y (2005) Stargazin reduces desensitization and slows deactivation of the AMPA-type glutamate receptors. J Neurosci 25:2682-2686.

Raman IM, Trussell LO (1995) Concentration-jump analysis of voltagedependent conductances activated by glutamate and kainate in neurons of the avian cochlear nucleus. Biophys J 69:1868-1879.

Romijn HJ, Habets AM, Mud MT, Wolters PS (1981) Nerve outgrowth, synaptogenesis and bioelectric activity in fetal rat cerebral cortex tissue cultured in serumfree, chemically defined medium. Brain Res 254:583-589.

Rosenmund C, Stern-Bach Y, Stevens CF (1998) The tetrameric structure of a glutamate receptor channel. Science 280:1596-1599.

Schnell E, Sizemore M, Karimzadegan S, Chen L, Bredt DS, Nicoll RA (2002) Direct interactions between PSD-95 and stargazin control synaptic AMPA receptor number. Proc Natl Acad Sci USA 99:13902-13907.

Sommer B, Keinanen K, Verdoorn TA, Wisden W, Burnashev N, Herb A, Kohler M, Takagi T, Sakmann B, Seeburg PH (1990) Flip and flop: a cell-specific functional switch in glutamate-operated channels of the CNS. Science 249:1580-1585.

Sommer B, Kohler M, Sprengel R, Seeburg PH (1991) RNA editing in brain controls a determinant of ion flow in glutamate-gated channels. Cell 67:11-19.

Stern-Bach Y, Russo S, Neuman M, Rosenmund C (1998) A point mutation in the glutamate binding site blocks desensitization of AMPA receptors. Neuron 21:907-918.

Sun Y, Olson R, Horning M, Armstrong N, Mayer M, Gouaux E (2002) Mechanism of glutamate receptor desensitization. Nature 417:245-253.

Swanson GT, Kamboj SK, Cull-Candy SG (1997) Single-channel properties of recombinant AMPA receptors depend on RNA editing, splice variation, and subunit composition. J Neurosci 17:58-69.

Tomita S, Chen L, Kawasaki Y, Petralia RS, Wenthold RJ, Nicoll RA, BredtDS (2003) Functional studies and distribution define a family of transmembrane AMPA receptor regulatory proteins. J Cell Biol 161:805-816.

Tomita S, Fukata M, Nicoll RA, Bredt DS (2004) Dynamic interaction of 
stargazin-like TARPs with cycling AMPA receptors at synapses. Science 303:1508-1511.

Tomita S, Stein V, Stocker TJ, Nicoll RA, Bredt DS (2005a) Bidirectional synaptic plasticity regulated by phosphorylation of stargazin-like TARPs. Neuron 45:269-277.

Tomita S, Adesnik H, Sekiguchi M, Zhang W, Wada K, Howe JR, Nicoll RA, Bredt DS (2005b) Stargazin modulates AMPA receptor gating and trafficking by distinct domains. Nature 435:1052-1058.

Trussell LO, Zhang S, Raman IM (1993) Desensitization of AMPA receptors upon multiquantal neurotransmitter release. Neuron 10:1185-1196.
Vandenberghe W, Nicoll RA, Bredt DS (2005a) Stargazin is an AMPA receptor auxiliary subunit. Proc Natl Acad Sci USA 102:485-490.

Vandenberghe W, Nicoll RA, Bredt DS (2005b) Interaction with the unfolded protein response reveals a role for stargazin in biosynthetic AMPA receptor transport. J Neurosci 25:1095-1102.

Wall MJ, Robert A, Howe JR, Usowicz MM (2002) The speeding of EPSC kinetics during maturation of a central synapse. Eur J Neurosci 15:785-797.

Yamazaki M, Ohno-Shosaku T, Fukaya M, Kano M, Watanabe M, Sakimura $\mathrm{K}$ (2004) A novel action of stargazin as an enhancer of AMPA receptor activity. Neurosci Res 50:369-374. 